\title{
THE STRONG DUAL OF A STRONGLY NUCLEAR SPACE NEED NOT BE NUCLEAR
}

\author{
JOE CROSS
}

\begin{abstract}
A strongly nuclear sequence space is exhibited whose strong dual is normed.
\end{abstract}

Let $l^{0}$ denote the intersection of all the $l^{p}$ spaces with $p>0$. Then $l^{0 \times}$, the Köthe dual of $l^{0}$, is easily seen to be $l^{\infty}$. The normal topology on $l^{\infty}$ induced by $l^{0}$ is the topology generated by the seminorms $\left(x_{n}\right) \mapsto \Sigma\left|a_{n} x_{n}\right|$, for $\left(x_{n}\right)$ in $l^{\infty}$ and $\left(a_{n}\right)$ in $l^{0}$.

Köthe $[2,(5)]$ has established that a sequence space $\lambda$ with the normal topology induced by a sequence space $\mu$ in the above sense is strongly nuclear if and only if $l^{0} \cdot \mu \supseteq \mu$. Since $l^{0}$ is closed under the operation $\left(x_{n}\right) \mapsto\left(\left|x_{n}\right|^{1 / 2}\right)$, it follows that the normal topology induced on $l^{\infty}$ by $l^{0}$ is strongly nuclear. But as is well known $[1,(5)]$, the bounded subsets of any perfect $\left(\lambda=\lambda^{\times \times}\right)$sequence space $\lambda$ with a nuclear normal topology are precisely the subsets of solid hulls of points; that is, for every bounded subset $B$ of $\lambda$, there is an element $\left(b_{n}\right)$ of $\lambda$ such that $\left|x_{n}\right| \leqslant\left|b_{n}\right|$ for all $n$, and for all $\left(x_{n}\right)$ in $B$. Hence the bounded subsets of $l^{\infty}$ under the normal topology induced by $l^{0}$ are the same as the bounded subsets of $l^{\infty}$ under its usual norm topology. Therefore $l^{\infty}$ under this strongly nuclear topology has a strong dual which is normed.

\section{REFERENCES}

1. G. Köthe, Über nukleare Folgenräume, Studia Math. 31 (1968), 267-271. MR 38 \#4946.

2. , Stark nukleare Folgenräume, J. Fac. Sci. Univ. Tokyo Sect. I 17 (1970), 291-296. MR 43 \#6689.

Department of Mathematics, New College, Sarasota, Florida 33578

Current address: 8550 156th Lane, N. W., Ramsey, Minnesota 55303

Received by the editors February 24, 1975.

AMS (MOS) subject classifications (1970). Primary 46A45, 46A15, 46A20.

Key words and phrases. Strongly nuclear space, dual nuclear space, uniformly strongly nuclear space, 